NOTE

\title{
Occurrence of spontaneous tumours of the renal proximal tubules in oscars Astronotus ocellatus
}

\author{
Oliver Hochwartner ${ }^{1, *}$, Gerhard Loupal ${ }^{2}$, William H. Wildgoose ${ }^{3}$, \\ Heike Schmidt-Posthaus ${ }^{4}$ \\ ${ }^{1}$ Schwarzenhaidestraße 41, 1230 Vienna, Austria \\ ${ }^{2}$ Institute of Pathology and Forensic Veterinary Medicine, University of Veterinary Medicine, Veterinärplatz 1, \\ 1210 Vienna, Austria \\ ${ }^{3}$ Midland Veterinary Surgery, 655 High Road, Leyton, London E10 6RA, UK \\ ${ }^{4}$ Centre for Fish and Wildlife Health, Institute of Animal Pathology, Laenggassstrasse 122, PO Box 8466, 3001 Berne, \\ Switzerland
}

\begin{abstract}
This report describes the occurrence of renal papillary cystic adenomas and adenocarcinomas in oscars Astronotus ocellatus Cuvier, 1829. Samples from 5 oscars with abdominal swelling were collected between 1996 and 2004 and compared to a published case from the USA. Macroscopically, all cases revealed a large, well-demarcated, greyish-brown nodular mass in a retroperitoneal position within the body cavity, and originating from the posterior kidney. Histologically, these neoplasms were composed of epithelial cells, which were arranged in papillary cystic tubular structures and partly covered by cilia. In this study, microscopic and ultrastructural examination confirmed that the origin of the neoplasm was the proximal tubules of the kidney.
\end{abstract}

KEY WORDS: Oscar · Astronotus ocellatus $\cdot$ Papillary cystic adenoma/adenocarcinoma $\cdot$ Kidney · Proximal tubules

Resale or republication not permitted without written consent of the publisher

\section{INTRODUCTION}

Like mammals, fish are affected by neoplastic proliferations and these are categorized according to mammalian tumour classifications. Primary neoplasms of the kidney are rarely described in fish in the literature (Huizinga \& Budd 1983, Lee et al. 1989, Petervary et al. 1996, Wildgoose 2001). The most common renal neoplasms in fish are nephroblastomas, which can be chemically induced or develop spontaneously and have been reported in trout and other commercially farmed fish species (Huizinga \& Budd 1983, Lee et al. 1989, Bailey et al. 1996, Baumann \& Okihiro 2000, Lumsden \& Marshall 2003). In addition, rainbow trout Oncorhynchus mykiss that are experimentally exposed to $\mathrm{N}$-methyl-N'-nitroN-nitrosoguanidine (MNNG), diethylnitrosamine or dimethylnitrosamine by immersion developed nephroblastomas (Bailey et al. 1996). Cystadenomas of the distal tubules and mesonephric duct may be caused by MNNG in rainbow trout (Lee et al. 1989).
The oscar Astronotus ocellatus Cuvier, 1829 is a member of the family Cichlidae that originates from the river systems of the Amazon and Paraná in South America (Riehl 2000). Oscars are very popular with tropical freshwater aquarists because of their size, attractive appearance and responsiveness to humans.

The first report of a renal neoplasm in an oscar in the USA was in 1996 (Petervary et al. 1996) but a definitive classification of this tumour was not given. The differential diagnoses based on histological findings included cystadenoma or adenocarcinoma of either the renal tubules, the collecting ducts, the mesonephric duct or the thyroid. Petervary et al. (1996) had the opportunity to review material on a further 3 cases from the Registry of Tumours of Lower Animals at the Smithsonian Institution (Washington, DC) that had remarkable histological similarities to their case. Later, these neoplasms were classified as urinary bladder tumours (Harshbarger \& Slatic 2001). In 2004, another renal tumour, a papillary cystic adenoma, was de- 
scribed in an oscar (Gumpenberger et al. 2004), and histological findings suggested that this originated from the proximal tubules of the kidney. Although all these tumours were fairly well differentiated and only occasionally invaded adjacent tissue, the fish were killed due to the severity of clinical signs resulting from the tumours' expansive growth, compression of adjacent organs and disturbance of normal kidney function (Petervary et al. 1996, Gumpenberger et al. 2004). Metastases were not found in any of these cases.

In this report, samples from 5 oscars with abdominal swelling were collected between 1996 and 2004: 3 from England, 1 from Austria and 1 from Switzerland. These tumours were compared histologically to material from the case described by Petervary et al. (1996). In addition, material from 4 of the 5 cases was examined using electron microscopy.

\section{MATERIALS AND METHODS}

All cases (Table 1) showed unilateral or bilateral abdominal swelling and a clinical history of lethargy, weakness and anorexia. The age of the fish was stated by the owner. Following physical examination, a provisional diagnosis of an intra-abdominal neoplasm with a poor prognosis was given and the fish were killed by immersion in a solution of buffered 3-aminobenzoic acid ethyl ester (MS 222, Argent Chemical Laboratories). Fresh wet mount preparations of samples from the skin, gills and intestinal contents were examined microscopically for parasites and the results are shown in Table 1. A complete post mortem examination was performed in all cases. The tumour masses were removed and fixed in $10 \%$ neutral buffered formalin, routinely processed for histological examination and stained with haematoxylin and eosin (H\&E).

Samples from Cases 1, 2, 3 and 4 were used for transmission electron microscopy. The formalin-fixed tissue samples were post-fixed in $4 \%$ glutaraldehyde and $1 \%$ osmium tetroxide and embedded in glycid ether (SERVA electrophoresis). Ultrathin sections were con- trasted with uranyl acetate and lead citrate before examination in an electron microscope (ZEISS EM 900).

\section{RESULTS}

Macroscopically, all tumours were well-demarcated, multi-lobular greyish-brown masses in a retroperitoneal position within the posterior body cavity (Fig. 1), which also contained varying amounts of clear to serosanguinous fluid. The tumours had a very soft friable texture and revealed a polycystic structure in cross-section. The cysts varied in size and were filled with an odourless fluid that varied from clear and colourless to slightly greenish or dark-brown.

Histologically, the neoplasms from all cases appeared similar. A major part of the normal renal tissue was replaced by a partially encapsulated, poorly to well-demarcated, densely cellular neoplastic mass that was embedded in a small amount of fibrovascular stroma (Fig. 2a). In one case, the tumour cells were

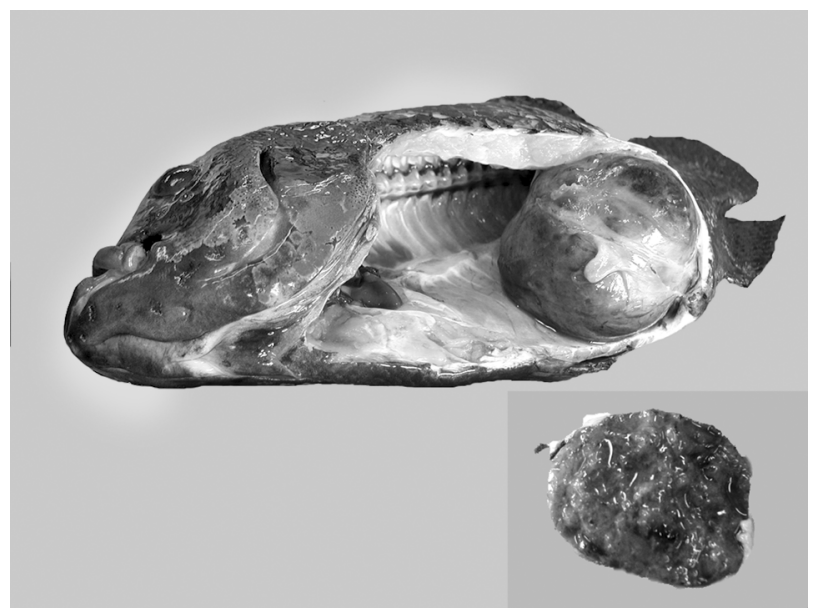

Fig. 1. Astronotus ocellatus. Macroscopic appearance of renal cystic adenoma in an oscar, Case 4 in Table 1. Insert: crosssection of the neoplasm (fresh tissue specimen)

Table 1. Astronotus ocellatus. Case specific data. (+) Mild, (++) moderate infestation with parasites, (-) no data available

\begin{tabular}{|c|c|c|c|c|c|c|}
\hline Case reference & Origin & Year & Age (yr) & Gender & Weight $(\mathrm{g}) /$ length $(\mathrm{cm})$ & Parasitological findings \\
\hline 1 & England & 1996 & Adult ${ }^{\mathrm{C}}$ & Female & $632 / 29$ & None \\
\hline 2 & England & 2000 & $\sim 10$ & Male & 1098/31 & None \\
\hline 3 & England & 2002 & $\geq 6$ & Unknown & $778 / 31.5$ & None \\
\hline $4^{\mathrm{a}}$ & Austria & 2002 & 8 & Female & $589 / 30$ & $\begin{array}{l}\text { Rectum: + Camallanus sp. } \\
\text { (Nematoda) }\end{array}$ \\
\hline 5 & Switzerland & 2004 & Adult $^{\mathrm{c}}$ & Female & $-/ 24.5$ & Gills: ++ Monogeneans \\
\hline $6^{\mathrm{b}}$ & USA & 1996 & $\geq 5$ & Unknown & $-/ 25$ & None \\
\hline
\end{tabular}


multifocally infiltrating into the adjacent renal tissue (Fig. 2a), while invasion was not detected in the other tumours. No metastases were found in other internal organs. The tumours were composed of epithelial cells that were arranged in tubular structures with a lumen of varying diameter. Several tubules were severely dilated and formed cystic structures. Multifocally, the epithelial cells formed papilliform projections into the
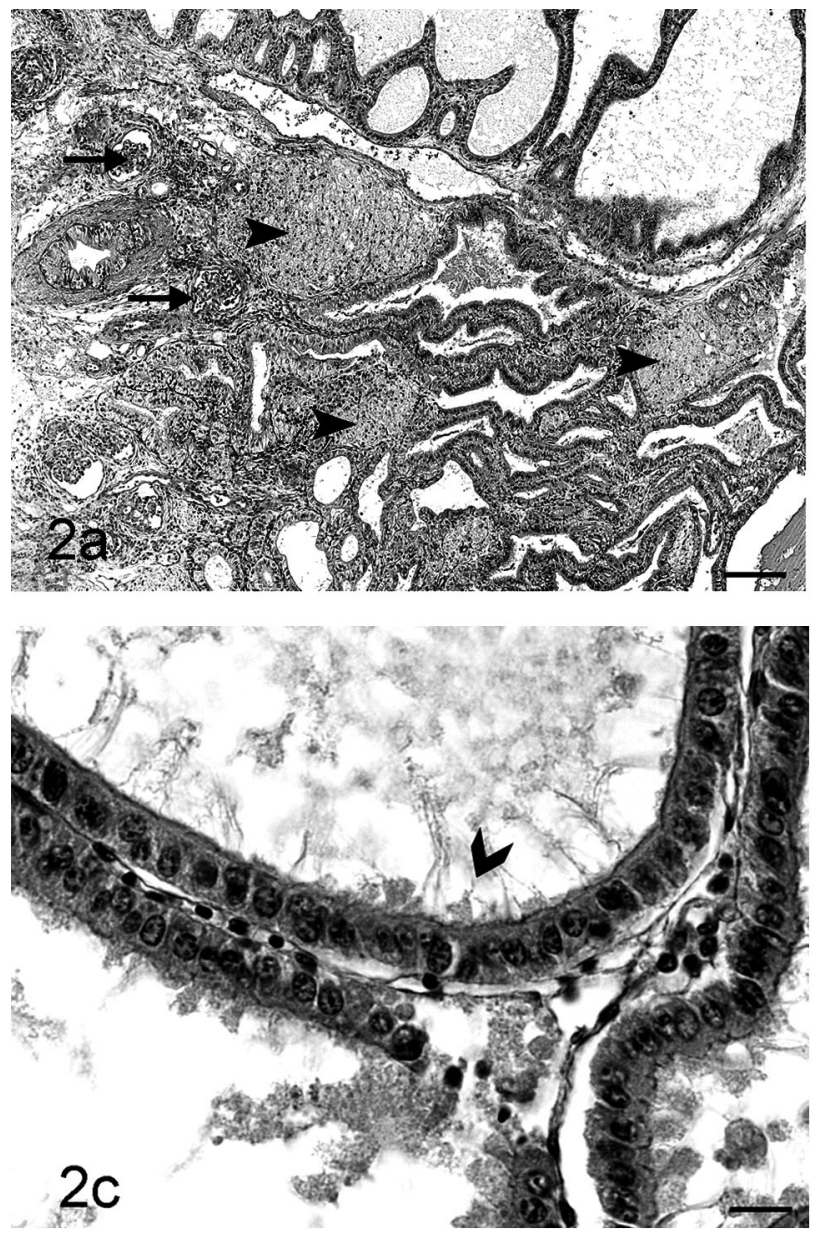

Fig. 2. Astronotus ocellatus. $(\mathrm{a}-\mathrm{c})$ Histological section (stain: haematoxylin and eosin) of the renal cystadenoma, Case 5 in Table 1. (a) Part of the normal renal tissue replaced by a nonencapsulated, poorly demarcated, infiltrative growing mass. Normal glomeruli (arrows) are distributed between the neoplastic structures; arrowheads indicate melanomacrophage centres; scale bar $=100 \mu \mathrm{m}$. (b) Severely dilated tubules forming cystic structures, papilliform projections into the lumen of the tubules (arrow), and melanomacrophage centres (arrowheads); scale bar $=100 \mu \mathrm{m}$. (c) Neoplastic cells that are cuboidal to highly prismatic with indistinct cell borders and a moderate amount of cytoplasm; nuclei basally to centrally located, round to ovoid with stippled to granular chromatin; cells covered by cilia (arrowhead); scale bar $=10 \mu \mathrm{m}$. (d) Ultrastructure of tumour cells, Case 2 in Table 1. Note the microvilli (arrowheads) and the cilia (arrow) on the surface of some cells; scale bar $=2.5 \mu \mathrm{m}$. Inset: higher magnification of the cilia; scale bar $=0.6 \mu \mathrm{m}$ lumen of the distended tubules (Fig. 2b). The neoplastic cells were cuboidal to highly prismatic and had indistinct cell borders with a moderate amount of eosinophilic cytoplasm. The nuclei of the epithelial cells were basally to centrally located, round to ovoid, with stippled to granular chromatin and 1 to 3 nucleoli (Fig. 2c). Several neoplastic cells were covered by cilia (Fig. 2c) and the mitotic rate was low $(<1 / 40 \times \mathrm{HPF}$
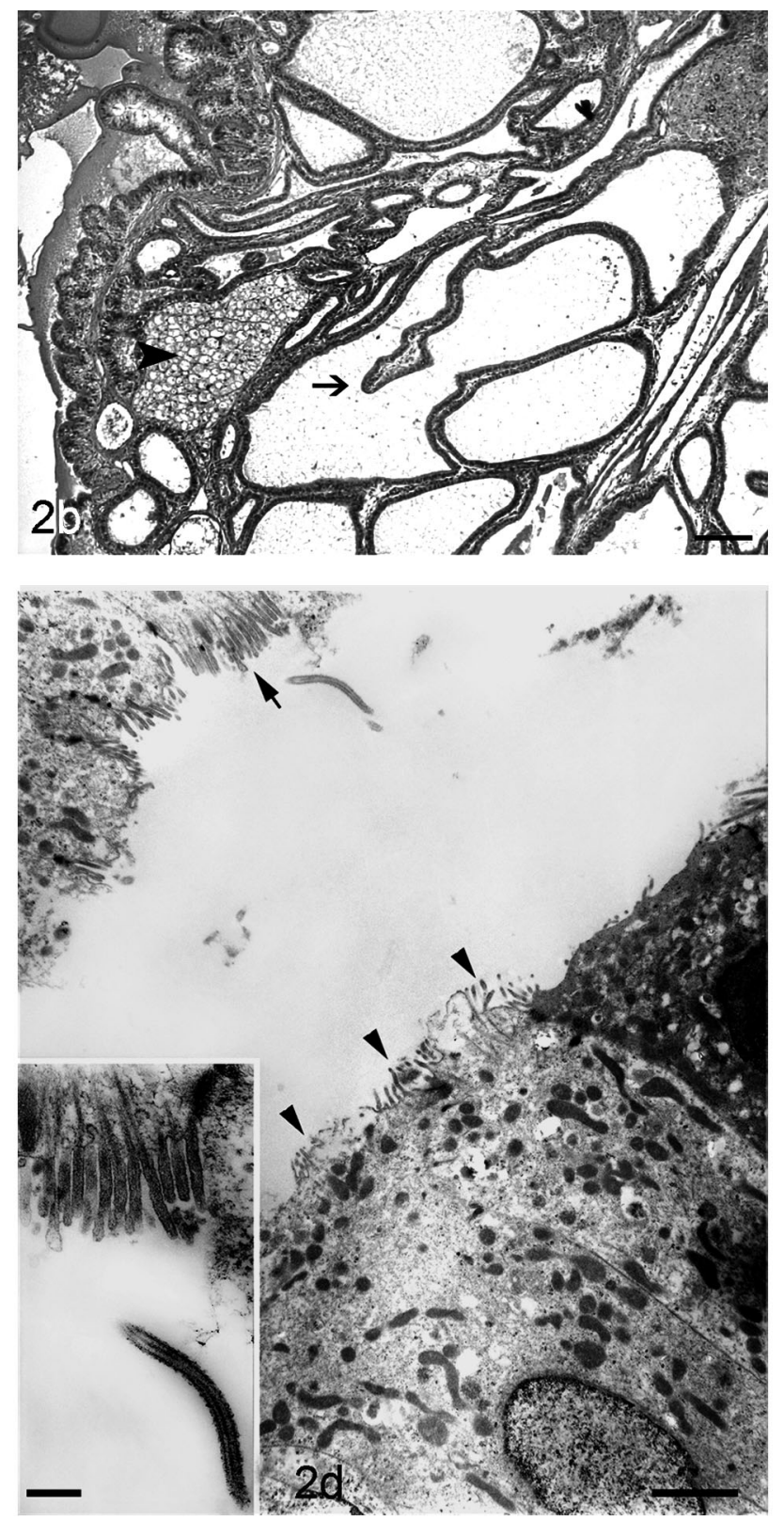
[high power field]). Several tubules were filled with eosinophilic granular to amorphic material that was admixed with macrophages and desquamated epithelial cells. Multifocally, there were aggregations of mainly macrophages, melanomacrophages and a few lymphocytes (Fig. 2b). Ultrastructural examination showed that many of the epithelial tumour cells had microvilli on their surface and some bore cilia (Fig. 2d).

According to their morphological appearance, the well-demarcated tumours were classified as papillary cystic adenomas and the infiltrative tumour was classified as an adenocarcinoma, all originating from the proximal tubules.

\section{DISCUSSION}

Renal neoplasms in oscars have been described by Petervary et al. (1996) and Gumpenberger et al. (2004) but the tissue origin of these tumours was not clearly identified. Petervary et al. (1996) suggested that they originated either from the renal tubules, thyroid or collecting/mesonephric ducts or urinary bladder. Based on their findings, the most likely diagnosis was an epithelial papilloma of mesonephric duct origin. Harshbarger \& Slatic (2001) suspected the urinary bladder as the origin of these tumours.

Based on the histological identification of cilia on the neoplastic cells, Gumpenberger et al. (2004) classified the neoplasm as a renal adenoma originating from the proximal tubules.

To demonstrate that the renal tumours from the oscars are probably all of identical origin, material from the case of Petervary et al. (1996) was compared to the 5 independent cases in this study. The clinical appearance of the Austrian case was published by Gumpenberger et al. (2004). Electron microscopical examination was used to confirm the presence of proximal tubule features. All kidney neoplasms investigated in this study were characterised by papillary cystic growth of epithelial cells and featured the morphological criteria of proximal tubule kidney cells, namely a columnar shape with basally or subcentrally located round nuclei, acidophilic cytoplasm, microvilli and cilia.

Tumours of the urinary bladder and other renal tissues such as the proximal and distal tubules, collecting ducts and mesonephric ducts have many characteristics in common, such as papillary cystic growth, absence of glomeruli and well differentiated cuboidal to columnar epithelial cells. However, the concomitant presence of cilia and microvilli identifies the proximal tubules as the source of the tumours investigated in this study. The cells of the neck segment feature only cilia, whereas the cells of the distal tubules have several microvilli and no cilia. The cells of collecting ducts, mesonephric duct and the urinary bladder lack both of these structures (Anderson \& Mitchum 1974, Oguri et al. 1982).

Chemically induced renal neoplasms have been reported in fish. In rainbow trout, papilliferous cystadenomas of the mesonephric duct, which have many characteristics in common with the neoplasms of the renal proximal tubules of oscars, can be experimentally induced by exposure to MNNG (Lee et al. 1989). Formalin and malachite green, which are commonly used as antiparasitic and antifungal substances in ornamental fish, are known to induce tumours in mammals (Homma et al. 1986, Fernandes et al. 1991, Srivastava et al. 2004) but there are no reports of this occurring in fish. Oscars are dominant predators and are frequently kept on their own in aquaria, and the need for recurrent antiparasitic therapy with the introduction of new fish is rarely required.

Inbreeding in oscars appears to be an unlikely factor since the tumour has been identified in several countries and in different breeds of oscars in this study. Thus, the occurrence of renal papillary cystic tumours in all the unrelated and separately maintained populations of oscars suggests a spontaneous development of these neoplasms. Spontaneous renal neoplasms in fish are very rare (Huizinga \& Budd 1983, Lee et al. 1989, Petervary et al. 1996). Nevertheless, 2 case reports of papillary cystic renal tumours in Astronotus ocellatus were published in 1996 and in 2004 (Petervary et al. 1996, Gumpenberger et al. 2004). Petervary et al. (1996) mentioned another 3 cases which were deposited at the Registry of Tumours of Lower Animals. Another 4 cases are presented here, 2 further cases in England have been confirmed histologically (W. H. Wildgoose pers. comm.) and others have been reported clinically (U. Dumpling \& L. Khoo pers. comm.). These case reports demonstrate the frequent appearance of spontaneous renal papillary cystic adenomas/adenocarcinomas in oscars.

Up to the present, this spontaneous neoplasm has only been reported in Astronotus ocellatus within the infraclass of the Teleostei. The rarity of these neoplasms and the apparent clustering of cases in oscars raise the possibility of a genetic predisposition in this species (Petervary et al. 1996, Gumpenberger et al. 2004), which should be further investigated on a molecular genetic basis. Furthermore, the frequent occurrence of primary renal neoplasms of proximal tubule origin and the lack of comparable tumours in any other fish species suggests that oscars may be a suitable model for renal tumour research in experimental oncology (Harshbarger \& Slatic 2001).

Acknowledgements. We thank G. Lewbart and D. Gillette for allocating their case of cystadenoma from 1996 for comparison and D. Gillette for photo editing. 


\section{LITERATURE CITED}

Anderson BG, Mitchum DL (1974) The excretory system. In: Anderson BG (ed) Atlas of trout histology. Wyoming Game and Fish Department, Bulletin No 13, p 37-41

Bailey GS, Williams DE, Hendricks JD (1996) Fish models for environmental carcinogenesis: the rainbow trout. Environ Health Perspect 104(Suppl 1):5-21

Baumann PC, Okihiro MS (2000) Cancer. In: Ostrander GK (ed) The laboratory fish. Academic Press, San Diego, CA, p 591-616

Fernandes C, Lalitha VS, Rao VK (1991) Enhancing effect of malachite green on the development of hepatic preneoplastic lesions induced by N-nitroso-diethylamine in rats. Carcinoginesis 12:839-845

Gumpenberger M, Hochwartner O, Loupal G (2004) Diagnostic imaging of a renal adenoma in a Red Oscar (Astronotus ocellatus Cuvier, 1829). Vet Radiol Ultrasound 45:139-142

Harshbarger JC, Slatic MS (2001) Lesser known aquarium fish tumor models. Mar Biotechnol 3:S115-S129

Homma Y, Nowels K, Oyasu R (1986) Effects of formalin induced injuries on urinary bladder carcinogenesis. Cancer Lett 32:117-123

Huizinga HW, Budd J (1983) Nephroblastoma in the smelt,

Editorial responsibility: Thomas Lang,

Cuxhaven, Germany
Osmerus mordax (Mitchill). J Fish Dis 6:389-391

> Lee BC, Hendricks JD, Bailey GS (1989) Rare renal neoplasms in Salmo gairdneri exposed to MNNG (N-methyl-N'-nitroN-nitrosoguanidine). Dis Aquat Org 6:105-111

Lumsden JS, Marshall S (2003) Sporadic neoplasms of farmed chinook salmon, Oncorhynchus tshawytscha (Walbaum) in New Zealand. J Fish Dis 26:393-399

Oguri M, Takashima F, Yokote M (1982) Kidney. In: Hibiya T (ed) Atlas of fish. Histology, normal and pathological features. Gustav Fischer Verlag, Stuttgart, p 94-103

> Petervary N, Gillette DM, Lewbart GA, Harshbarger JC (1996) A spontaneous neoplasm of the renal collecting ducts in an Oscar, Astronotus ocellatus (Cuvier), with comments on similar cases in this species. J Fish Dis 19: $279-281$

Riehl R (2000) Buntbarsche, Cichliden; Familie Cichlidae. In: Riehl R, Baensch H (eds) Aquarien Atlas, Vol 1. Mergus Verlag, Melle, p 682

Srivastava S, Sinha R, Roy D (2004) Toxicological effects of malachite green. Aquat Toxicol 66:319-329

Wildgoose WH (2001) Internal disorders. In: Wildgoose WH (ed) BSAVA manual of ornamental fish, 2nd edn. British Small Animal Veterinary Association, Gloucester, p 123-134

Submitted: May 26, 2009; Accepted: September 18, 2009 Proofs received from author(s): February 1, 2010 